\title{
Listeners rapidly use unexpected information to update their predictions: Evidence from eye-movements
}

\author{
Wing-Yee Chow \& Di Chen (University College London) \\ wingyee.chow@ucl.ac.uk
}

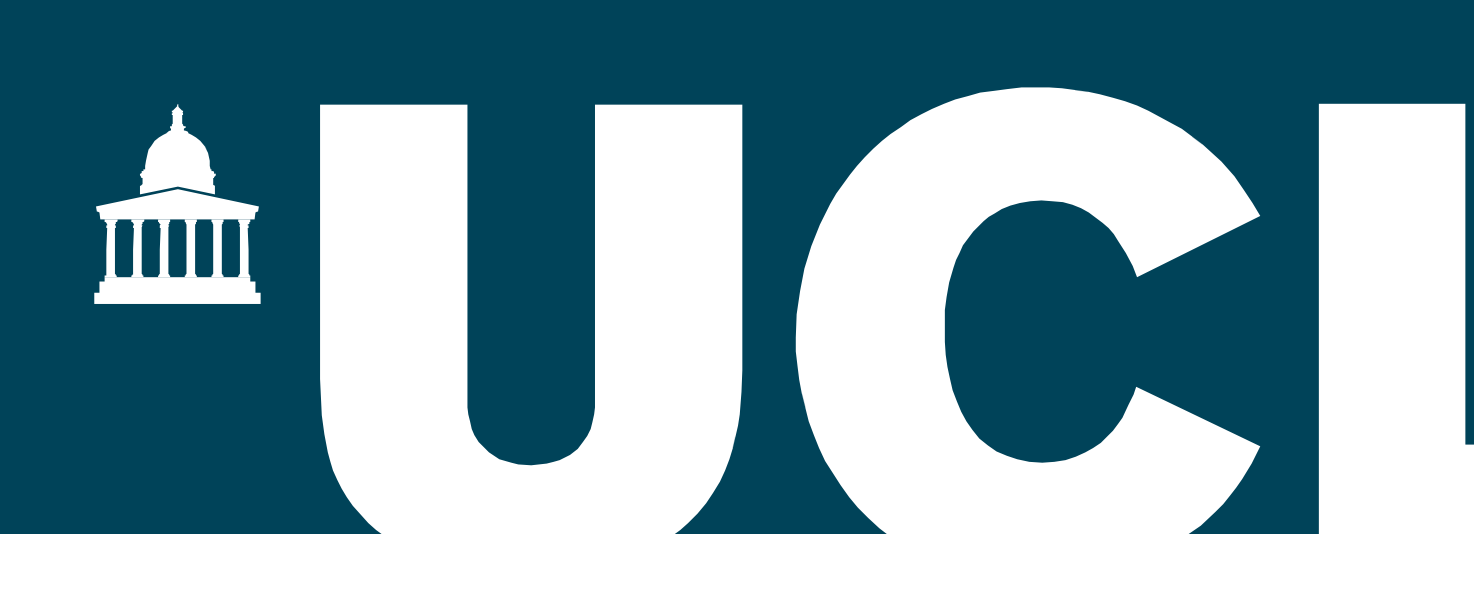

\section{INTRODUCTION}

Comprehenders generate predictions about upcoming language input on the fly. ${ }^{[1-5]}$

- Correct predictions can facilitate processing, but the expressive nature of language means that predictions often turn out to be wrong.

\section{This book has three}

\section{We can detect prediction errors very quickly.}

The burglar had no trouble locating the secret family safe. Of course, it was situated behind a... ㄷ "groot" "grote"

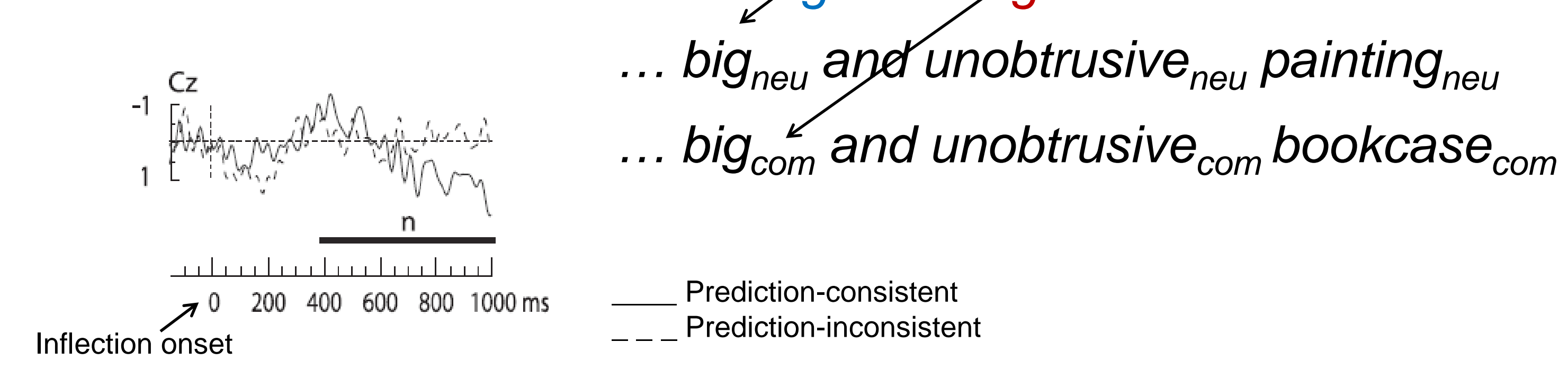

Listeners' ERP response was immediately sensitive to the mismatch between a pre-nominal cue (e.g., grammatical gender of an adjective) and the predicted (and yet to appear) noun. [2-5]

\section{$\rightarrow$ What do we do once we have detected a prediction error?}

\section{The Present Study}

Goal: To examine if and how quickly listeners can use prediction-inconsistent cues to revise their predictions.

Strategy: To capitalize on the rich classifier system in Mandarin Chinese to provide prediction-inconsistent cues that may also be used for prediction revision.

In Mandarin Chinese, a noun must be preceded by a classifier when it is modified by a demonstrative or numeral. [6]

$$
\begin{aligned}
& \text { (1) san *(bei) kafe (2) yi * (ben) shu } \\
& \text { 'three cups of coffee' 'one book' }
\end{aligned}
$$

General classifiers

Specific classifiers

$$
\begin{array}{ll}
\begin{array}{l}
g e \\
\text { 'xie' } \text { 些 }
\end{array} \begin{array}{l}
\text { book, magazine, novel, } \\
\text { dictionary, student, line, } \\
\text { cake, fish, country, apple, }
\end{array} & \text { 'ben' 本 } \begin{array}{l}
\text { book, magazine, } \\
\text { novel, dictionary }
\end{array}
\end{array}
$$$$
\text { house, phone }
$$

Previous studies have shown that

- comprehenders can quickly use specific classifiers to identify the target referent ${ }^{[7]}$, and

prediction-inconsistent classifiers elicited a larger N400 response than prediction-consistent classifiers. ${ }^{[5]}$

Question: Do comprehenders revise their predictions for an upcoming noun when they encounter a prediction-inconsistent classifier?

\section{ACKNOWLEDGEMENTS}

We thank Ziren Zhou for help with stimulus development. This research is funded by BA/Leverhulme (SRG000032444).

\section{METHODS}

Visual world eye-tracking paradigm with a $2 \times 2$ design

- Noun expectancy: expected (coffee) vs. unexpected (cake)

- Classifier type: specific (informative) vs general (uninformative control)

Anna zai xingbake mai-le yi...

Anna at Starbucks bought one

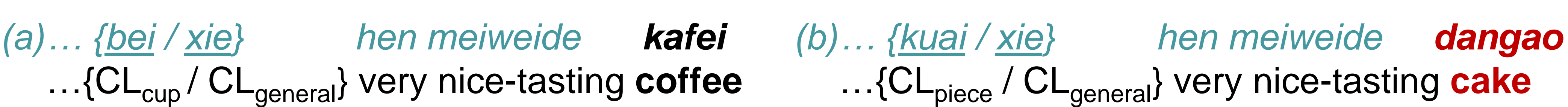

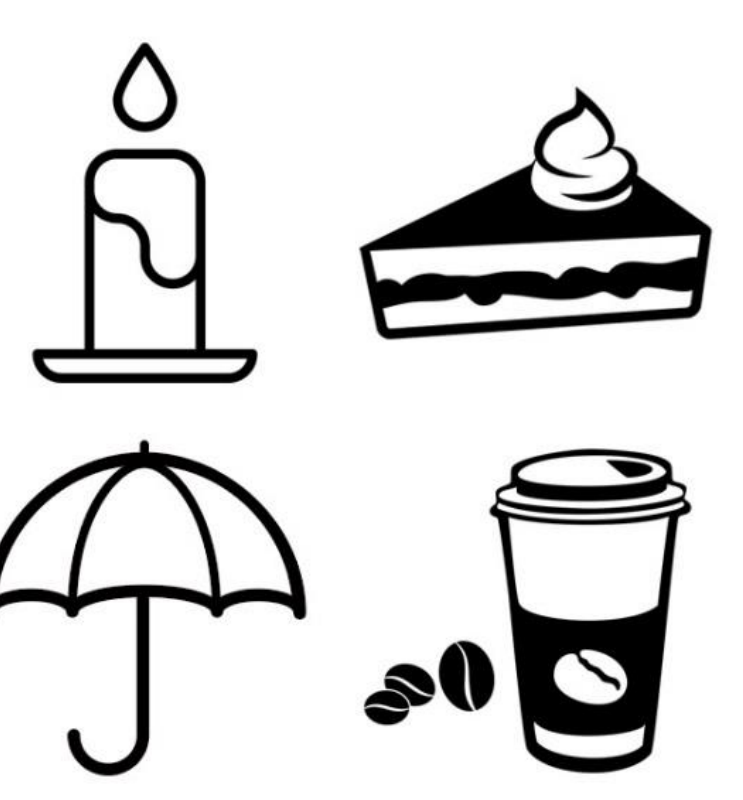

- $\mathrm{n}=23$ native Mandarin speakers; 60 experimental items (normed for cloze probability; $\mathrm{n}=90$ ) +30 fillers

- Four objects on the visual display, depicting the expected noun (coffee), unexpected noun (cake) and two unrelated nouns; $1500 \mathrm{~ms}$ preview prior to spoken stimulus onset; eye-movements sampled at $300 \mathrm{~Hz}$

Specific classifier for expected noun ("bei") incompatible with unexpected noun ; specific classifier for unexpected noun ("kuai") incompatible with expected noun.

General classifiers: compatible with both expected and unexpected nouns

\section{Hypotheses ANd Predictions}

I. If listeners expect "coffee" more strongly than "cake" before hearing the classifier $\rightarrow$ More looks to the target object in the expected than unexpected noun condition prior to CL onset

II. If and when listeners detect a mismatch between the classifier and their predicted noun

$\rightarrow$ Looks to the expected object in the unexpected noun condition should decrease when the classifier is specific (relative to the general classifier condition)

III. If and when listeners use the prediction-inconsistent classifier to revise their noun predictions $\rightarrow$ Looks to the unexpected (target) object in the unexpected noun condition should increase when the classified is specific (relative to the general classifier condition)

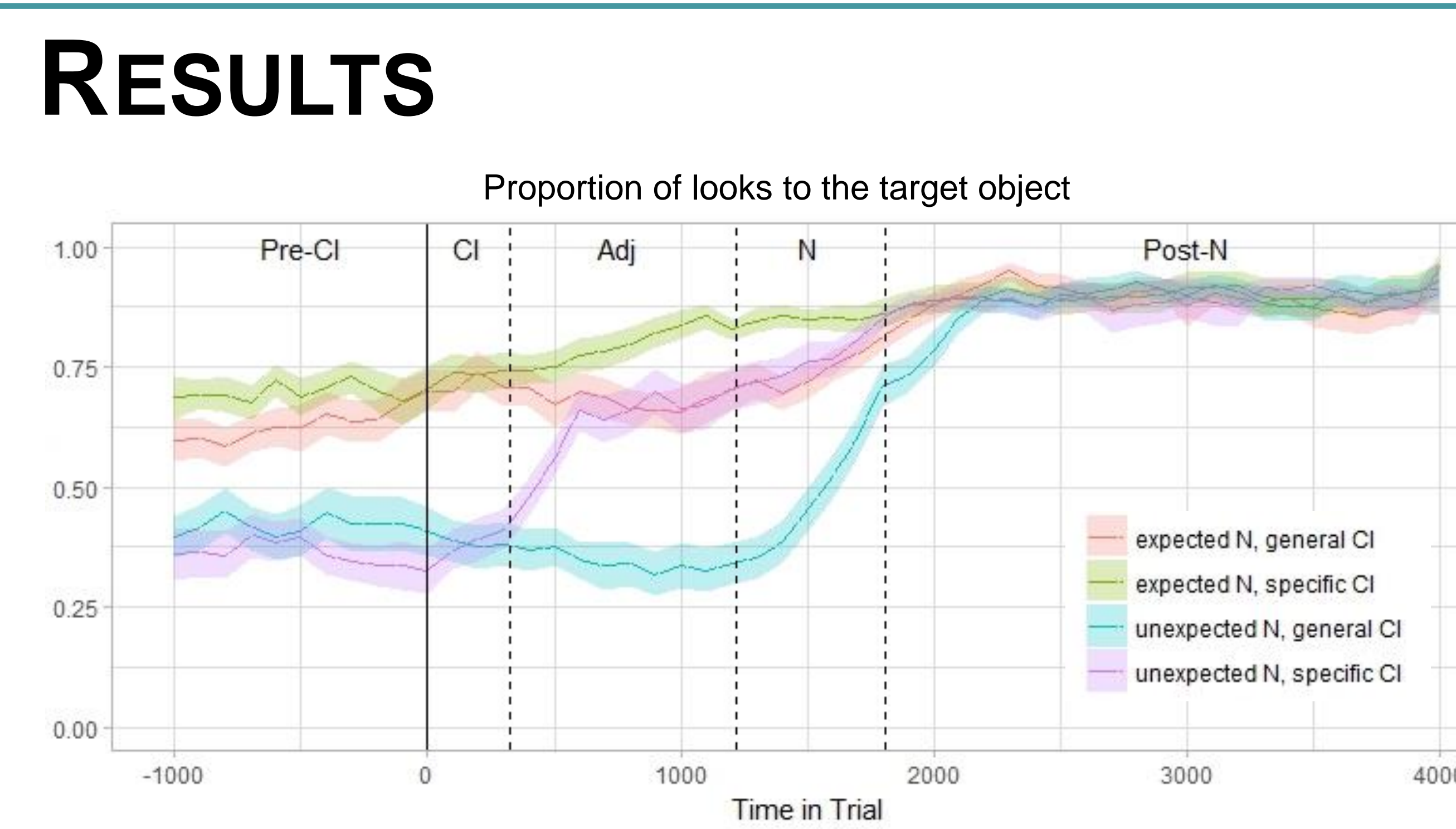

Window analysis on proportion of looks to target object $2 \times 2$ logistic mixed models with maximal random effects structure

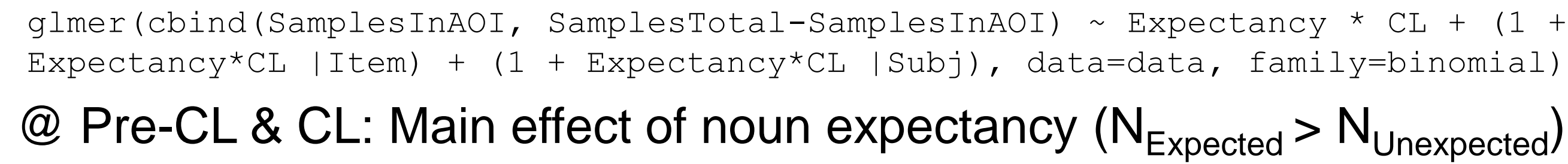
$@$ Adj: Main effects of both IVs ( $\left.\mathrm{N}_{\text {Expected }}>\mathrm{N}_{\text {Unexpected }} ; \mathrm{CL}_{\text {Specific }}>\mathrm{CL}_{\text {General }}\right)$ @ N: Main effects \& interaction (larger CL type effect for unexpected N) $@$ Post-N: n.s. as all conditions reached ceiling

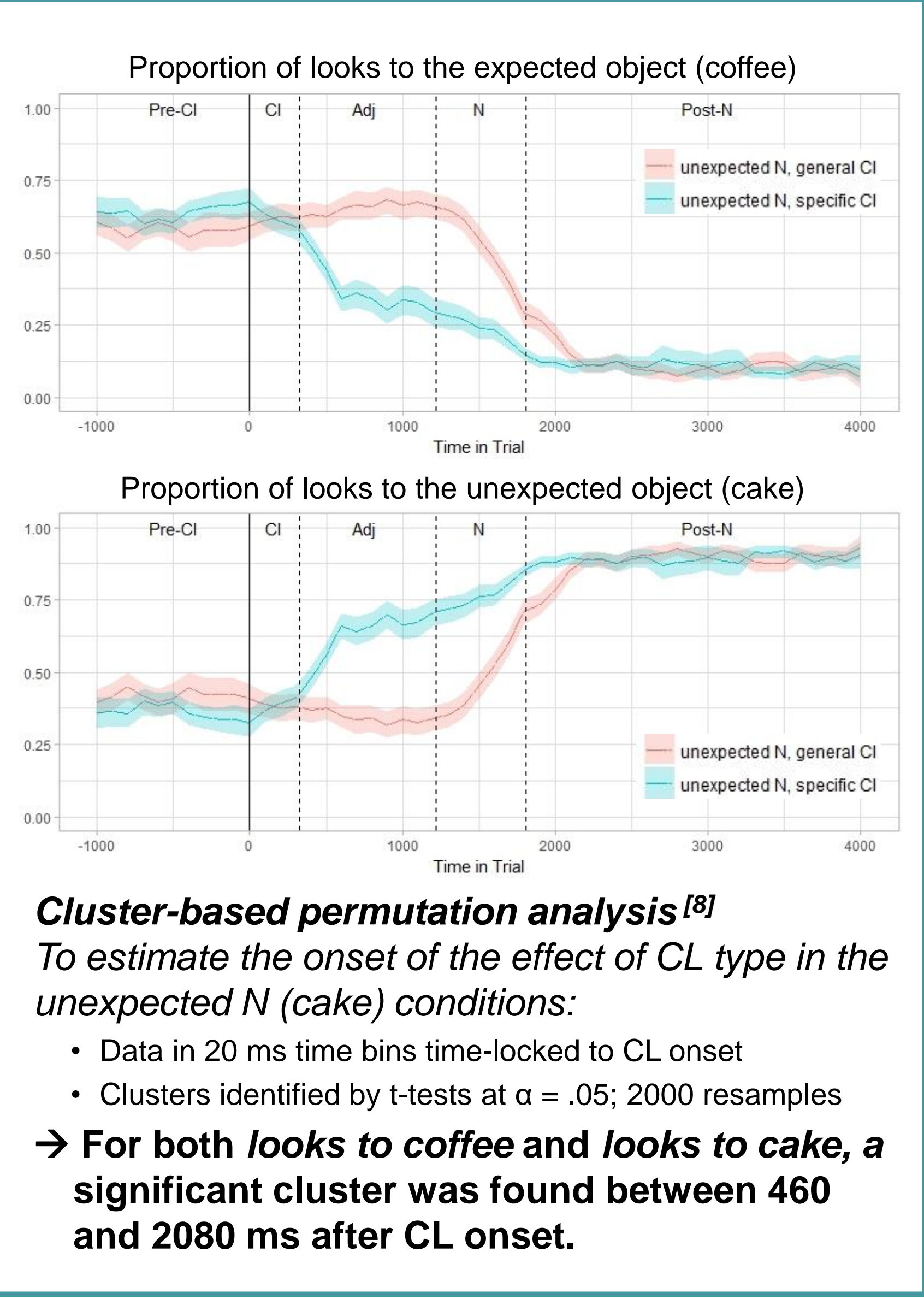

\section{DISCUSSION}

1. Listeners were more likely to look at coffee than cake prior to $C L$ onset $\rightarrow$ Evidence for listeners' initial $\mathrm{N}$ predictions

2. In the unexpected $\mathrm{N}$ condition, looks to expected object (coffee) dropped immediately after the specific $\mathrm{CL}\left(\mathrm{CL}_{\text {piece }}\right)$

$\rightarrow$ Listeners can quickly detect a mismatch between the $\mathrm{CL}$ and the predicted $\mathrm{N}$, and inhibit their existing prediction within $460 \mathrm{~ms}$ after $\mathrm{CL}$ onset

3. As soon as they looked away from the expected object, listeners directed their gaze towards the target object

$\rightarrow$ With a restricted visual context (where only a handful of candidates are available) listeners can revise their prediction as quickly as they can detect a prediction error.

Next step: to examine prediction revision in a more open-ended context (i.e., without visual display) using ERPs.

\section{REFERENCES}

Kamide, Y. (2008). Anticipatory Processes in Sentence Processing. Linguistics and Language Compass, 2(4), 647-670.

2. Wicha, N. Y. Y., Moreno, E. M., \& Kutas, M. (2004). Anticipating words and their gender: an eventrelated brain potential study of semantic integration, gender expectancy, and gender agreement in Spanish sentence reading. Journal of Cognitive Neuroscience, 16(7), 1272-88.

3. Van Berkum, J. J. A., Brown, C. M., Zwitserlood, P., Kooijman, V., \& Hagoort, P. (2005). Anticipatin upcoming words in discourse: evidence from ERPs and reading times. Journal of Experimental Psychology. Learning, Memory, and Cognition, 31(3), 443-467.

4. Szewczyk, J. M., \& Schriefers, H. (2013). Prediction in language comprehension beyond specific words: An ERP study on sentence comprehension in Polish. Journal of Memory and Language,
68(4), 297-314

5. Kwon, N., Sturt, P., \& Liu, P. (2017). Predicting semantic features in Chinese: Evidence from ERPs Cognition, 166, 433-446.

6. Gao, M. Y., \& Malt, B. C. (2009). Mental representation and cognitive consequences of Chines individual classifiers. Language and Cognitive Processes, 24, 1124-1179

. Klein, N. M., Carlson, G. N., Li, R., Jaeger, T. F., \& Tanenhaus, M. K. (2012). Classifying and massifying incrementally in Chinese language comprehension. In D. Massam (Ed.), Count and Mass Across Languages (pp. 261-282). Oxford, UK: Oxford University Press.

8. Maris, E., \& Oostenveld, R. (2007). Nonparametric statistical testing of EEG- and MEG-data. Journal of Neuroscience Methods, 164(1), 177-190. 